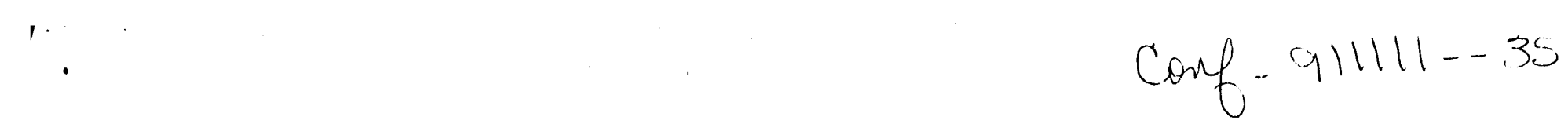

\title{
HYDROGEN EMBRITTLEMENT CONSIDERATIONS IN NIOBIUM-BASE ALLOYS FOR APPLICATION IN THE ITER DIVERTOR
}

ANL/CP- -73174

DE92 007368

\author{
D. T. Peterson ${ }^{+}$, A. B. Hull ${ }^{\dagger}$ and B. A. Loomis ${ }^{\dagger}$ \\ +Ames Laboratory, Iowa State University, Ames, Iowa, 50011 \\ †Argonne National Laboratory, 9700 S. Cass Ave., \\ Argonne, Illinois, 60439, U.S.A.
}

The ITER divertor will be subjected to hydrogen from aqueous corrosion by the coolant and by transfer from the plasma. Global hydrogen concentrations are one factor in assessing hydrogen embrittlement but local concentrations affected by source fluxes and thermotransport in thermal gradients are more important considerations. Global hydrogen concentrations in some corrosion-tested alloys will be presented and interpreted. The degradation of mechanical properties of $\mathrm{Nb}$-base alloys due to hydrogen is a complex function of temperature, hydrogen concentration, stresses and alloy composition. The known tendencies for embrittlement and hydride formation in $\mathrm{Nb}$ alloys are reviewed.

*Work supported by the Office of Fusion Energy, U.S. Department of Energy under contract W-31-109-Eng-38.

\section{DISCLAIMER}

\footnotetext{
This report was prepared as an account of work sponsored by an agency of the United States Government. Neither the United States Gnvernment nor any agency thereof, nor any of their employees, makes any warranty, express or implied, or assumes any legal liability or responsibility for the accuracy, completeness, or usefulness of any information, apparatus, product, or process disclosed, or represents that its use would not infringe privately owned rights. Reference herein to any specific commercial product, process, or service by trade name, trademark, manufacturer, or otherwise does not necessarily constitute or imply its endorsement, recommendation, or favoring by the United States Government or any agency thereof. The views and opinions of authors expressed herein do not necessarily state or reflect those of the United States Government or any agency thereof.
} 
Introduction

Niobium-based alloys have some attractive properties and characteristics for the ITER divertor structure as described by Kuroda et al [1] but the use of these alloys requires satisfactory solutions to the problems brought about by the possibility of hydrogen introduction. Hydrogen could arise from the corrosion of niobium alloys by the water coolant, by injection or solution of hydrogen, deuterium and tritium from the plasma and by nuclear reactions such as the n,p reaction. After introduction into the niobium alloy, hydrogen could be lost to the coolant by an electrochemical or chemical oxidation reaction, could be evolved into the vacuum space of the plasma chamber or could accumulate as hydride precipitates. These potential sources and sinks for the hydrogen isotope population need to be investigated and characterized individually in order to be able to manage hydrogen problems in the divertor structure with a high level of assurance.

\section{Hydrogen from Corrosion}

Niobium has a high level of corrosion resistance, as summarized by Lupton, Aldinger and Schulze [2], to water and to many acidic solutions because of a passivating $\mathrm{Nb}_{2} \mathrm{O}_{5}$ layer. If this layer is dissolved as by basic solutions or solutions containing flouride ion, the niobium metal will be seriously corroded and may also be embrittled by absorbed hydrogen. The corrosion reaction with water can, in part, be written as:

$2 \mathrm{Nb}(\mathrm{s})+5 \mathrm{H}_{2} \mathrm{O}_{(\mathrm{l})} \rightarrow \mathrm{Nb}_{2} \mathrm{O}_{5(\mathrm{~s})}+5 \mathrm{H}_{2}$.

The hydrogen generated by this reaction can be evolved as hydrogen gas, oxidized by molecular oxygen or other oxidants in the coolant or it can be absorbed by the niobium metal or alloy. The latter course could lead to serious problems with hydrogen embrittlement if the extent of corrosion were significant. 
The hydrogen concentrations of a selected number of niobium and niobium alloy specimens that had been corrosion tested as described by Hull et. al. [3] were measured by hot vacuum extraction method. The niobium alloy specimens were heated under vacuum to $1073 \mathrm{~K}$ and the gas evolved was pumped into a calibrated volume by a mercury diffusion pump and the pressure measured with a McLoed guage. The specimens were not cleaned nor treated to remove the niobium oxide layer produced by corrosion testing. This layer might contain a small amount of occluded water but in an incrementally heated specimen that evolved $153 \mathrm{ppm}$ of gas, only $10 \mathrm{ppm}$ was evolved below $773 \mathrm{~K}$ and might have been due to occluded water. As a result, the evolved gas was all considered to be hydrogen.

The hydrogen analyses of $\mathrm{Nb}-2.5 \%$ Mo alloys after being corrosion tested for various times are shown in Table I. The hydrogen content, in general, increased with time although the 90 day specimen had an anomalously high concentration. The concentrations were all above the 120 ppm concentration limit at which Oakwood and Daniels [4] had found hydrogen to reduce ductility at room temperature. These alloys had been evaluated by a room ternperature bend test by Hull et. al. [3] and all had been given a rating of 5 on a scale in which 1 was the most ductile and 5 was the most brittle. The concentration of hydrogen in the specimens was compared to the stoichiometric amount of hydrogen that could have been generated by the corrosion reaction. The corrosion weight gain was taken to be entirely due to oxidation of niobium by Eq. 1 in order to calculate the possible hydrogen concentrations. The specimens all had absorbed only a fraction of the available hydrogen. The high result at 90 days was due to a larger fraction of the hydrogen being absorbed rather than more extensive corrosion of the specimen.

The hydrogen concentrations found in a series of niobium alloys after 30 days of corrosion testing is shown in Table II. The hydrogen concentrations varied by more than a factor of ten and the percentage of hydrogen absorbed varied almost as much. The brittleness index correlated quite well with the hydrogen concentration. It appears that alloying niobium can not only change the 
corrosion rate but also the hydrogen absorption process and quite likely the resistance of the alloys to hydrogen embrittlement. Analysis of additional corrosion tested specimens would give more information on the effect of alloying on hydrogen absorption.

The hydrogen concentrations found in these corrosion tested specimens are much higher than would be introduced in similar times in a divertor component. The corrosion coupons were only $0.127 \mathrm{~mm}$ thick and were corroded on both sides. A proposed niobium divertor plate as described by Mattas [5] would be $2.0 \mathrm{~mm}$ thick and exposed to water corrosion on only one side. This difference would be expected to lower the hydrogen concentration by a multiplicative factor of 0.0318 and lower the concentration in pure niobium from 730 as given in Table II to $23 \mathrm{ppm}$. The slow rate of corrosion coupled with the rapid diffusion of hydrogen in niobium would insure that the concentration at all times be uniform across the thickness of a $2.0 \mathrm{~mm}$ thick niobium section. The time required for saturation of a $2.0 \mathrm{~mm}$ section from one side, based on the diffusion coefficient for hydrogen in niobium reported by Peterson and Herro [6], is only 22 minutes, which is very short compared to the corrosion times.

Thermotransport of Hydrogen and its Isotopes

The ITER divertor may have a large temperatuere difference between the hot plasma side and the water cooled side as reported by Mattas [5]. The temperature gradient can produce a hydrogen concentration gradient due to thermotransport of hydrogen and its isotopes. The concentration gradient is related to the thermal gradient at steady state by the following: $\ln \frac{\mathrm{C}_{1}}{\mathrm{C}_{2}}=\frac{\mathrm{Q}^{*}}{\mathrm{R}}\left(\frac{1}{\mathrm{~T}_{1}}-\frac{1}{\mathrm{~T}_{2}}\right)$

where $C_{1}$ and $C_{2}$ are he hydrogen concentrations and $T_{1}$ and $T_{2}$ are the temperatures at two points, $\mathrm{Q}^{*}$ is the heat of transport and $\mathrm{R}$ is the gas constant. Values for the heat of transport, $\mathrm{Q}^{*}$, are reported for hydrogen and deuterium in niobium by Peterson and Smith [7], in niobium alloys 
by Peterson and Smith [8] and for tritium in niobium by Sugasaki et al [9]. These values are shown in Table III along with the concentration ratios that would be produced by temperatures of $1250 \mathrm{~K}$ and $700 \mathrm{~K}$ as postulated for an ITER plate by Mattas [5]. The calculated concentration profile for deuterium in $\mathrm{Nb}-10 \mathrm{~V}$ for such a temperature difference in a $2.0 \mathrm{~mm}$ section thickness is shown in Fig. 1. The thermotransport effect on the concentration distribution becomes even larger at lower temperatures and a difference between $370 \mathrm{~K}$ and $300 \mathrm{~K}$ would produce the same concentration ratios as given in Table III. The influence of thermotransport on hydrogen fluxes in a fusion reactor have been discussed quite cogently by Sugasiaki and Furuya [10]. The times required to reach the thermotransport steady state depend on the diffusion coefficient but generally range from a few minutes to a few hours. These are short enough so that the effect of thermotransport may need to be considered in fusion reactors.

\section{Hydrogen Embrittlement of Niobium}

The introduction of hydrogen into niobium produces significant changes in the mechanical properties, particularly the reduction in area at fracture. If the concentration of hydrogen exceeds the terminal solid solubility limit, a hydride phase is formed which is always weak in tension and easily fractured if the overall stress is above the yield strength. Even when the concentration is below the solubility limit, hydride phases can be formed in the triaxially stressed area at a crack tip, assist the crack growth process and lead to fracture with very little reduction in area. This induced hydride embrittlement results in a ductile-brittle transition in tensile or impact tests even when there was none in the metal without hydrogen as reported by Oakwood and Daniels [4]. Alloying niobium can produce a beneficial increase in the terminal solid solubility of niobium-vanadium alloys as reported by Peterson and Herro [6]. Alloying niobium with varadium also has been reported by Owen et al [11] to reduce the embrittlement caused by hydrogen at all temperatures. In the case of vanadium alloys, the addition of titanium reduced the embrittling effect of hydrogen whereas the addition of chromium substantially increases hydrogen embrittlement. There appear to 
be quite good prospects for increasing the solubility of the hydride phase and of increasing the tolerance for hydrogen by developing appropriate niobium alloys.

\section{Summary}

1. The corrosion rate of niobium alloys is quite low even at $573 \mathrm{~K}$ and only a fraction of the hydrogen produced by corrosion was absorbed. The projected hydrogen concentrations in an ITER divertor plate are below the levels expected to cause embrittlement.

2. Corrosion resistance, hydrogen absorption and resistance to embrittlement of niobium can all quite likely be significantly improved by alloying.

3. Thermotransport of hydrogen may perturb the hydrogen concentration and needs to be considered. 


\section{References}

[1] T. Kuroda et al, ITER Plasma Facing Components, ITER Documentation Series, No 30, International Atomic Energy Agency, Vienna (1991).

[2] D. Lupton, F. Aldinger and K. Schulze, in: Niobium, Proceedings of the International Symposium. (The Metallurgical Society of AIME, Warrendale, PA. 1981) p 533.

[3] A. B. Hull, I. Purdy and B. A. Loomis, in : Proceeding Fifth International Conference on Fusion Reactor Materials ( 1991).

[4] T. G. Oakwood and R. G. Daniels, Trans. TMS-AIME. 242 (1968) 1327.

[5] R. F. Mattas, ITER Divertor Plate Performance and Lifetime Considerations, ANL/FPP/TM246, Argonne National Laboratory (March 1990).

[6] D. T. Peterson and H. M. Herro, Metall. Trans. 17A (1986) 645.

[7] D. T. Peterson and M. F. Smith, Metall. Trans. 13A (1982) 821.

[8] D. T. Peterson and M. F. Smith, Metall. Trans. 14A (1983) 871.

[9] M. Sugisaki, S. Mukai, K. Idemitsu and H. Furuya, J. Nucl. Mater. 115 (1983) 91.

[10] M. Sugisaki. H. Furuya, J. Nucl. Mater. 128 \& 129 (1984) 734.

[11] C. V. Owen, D-S. Cheong, O. Buck and T. E. Scott, Metall. Trans. 15A (1984) 147. 


\begin{tabular}{|c|c|c|c|}
\hline Time, days & $\begin{array}{c}\text { Hydrogen } \\
\text { Concentration, ppm }\end{array}$ & $\begin{array}{c}\text { Percent } \mathrm{H} \\
\text { Captured } \\
\end{array}$ & $\begin{array}{c}\text { Brittleness } \\
\text { Index } \\
\end{array}$ \\
\hline 30 & 207 & 16 & 5 \\
\hline 60 & 308 & 17 & 5 \\
\hline 90 & 942 & 40 & 5 \\
\hline 120 & 386 & 15 & 5 \\
\hline
\end{tabular}


Table II Hydrogen Concentrations in Corrosion Tested Niobium Alloys after 30 Days

\begin{tabular}{lcrc}
\hline Alloy & $\begin{array}{c}\text { Hydrogen } \\
\text { Concentration, ppm }\end{array}$ & $\begin{array}{c}\text { Percent } \mathrm{H} \\
\text { Captured }\end{array}$ & $\begin{array}{c}\text { Brittleness } \\
\text { Index }\end{array}$ \\
\hline & & & \\
Pure Nb & 730 & 16 & 5 \\
$\mathrm{Nb}-2.5 \mathrm{Zr}$ & 85 & 7 & 1 \\
$\mathrm{Nb}-2.5 \mathrm{~V}$ & 269 & 35 & 5 \\
$\mathrm{Nb}-2.5 \mathrm{Hf}$ & 120 & 8 & 2 \\
$\mathrm{Nb}-2.5 \mathrm{Ta}-2.5 \mathrm{Ti}$ & 63 & 5 & 2 \\
$\mathrm{Nb}-2.5 \mathrm{Mo}$ & 207 & 16 & 5 \\
\end{tabular}


Table III Heat of Transport for Hydrogen Isotopes and Concentration Ratios in Niobium Alloys

\begin{tabular}{lrl}
\hline System & $\mathrm{Q}^{*}, \mathrm{~kJ}$ & $\mathrm{C}_{1} / \mathrm{C}_{2}$ \\
\hline & & \\
$\mathrm{H}$ in $\mathrm{Nb}$ & 9.4 & 0.49 \\
$\mathrm{D}$ in $\mathrm{Nb}$ & 16.3 & 0.29 \\
$\mathrm{~T}$ in Nb & 18.8 & 0.24 \\
$\mathrm{H}$ in Nb-10V & 15.8 & 0.30 \\
D in Nb-10V & 20.4 & 0.21 \\
\hline
\end{tabular}




\section{Figure Captions}

Fig. 1 Dueterium Concentration in Nb-10V Alloy Section With and Without a Temperature Gradient. 


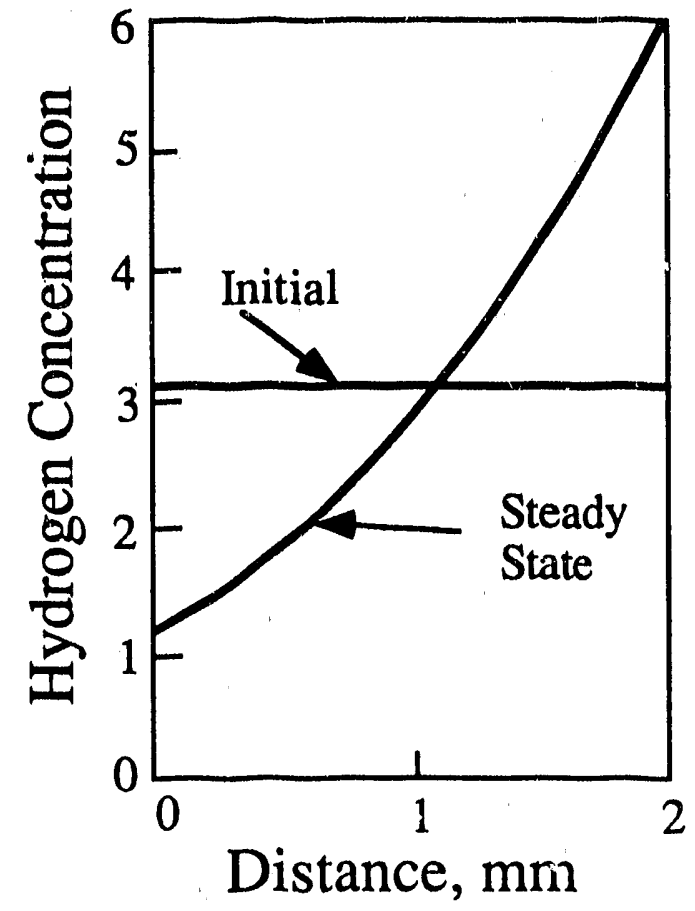



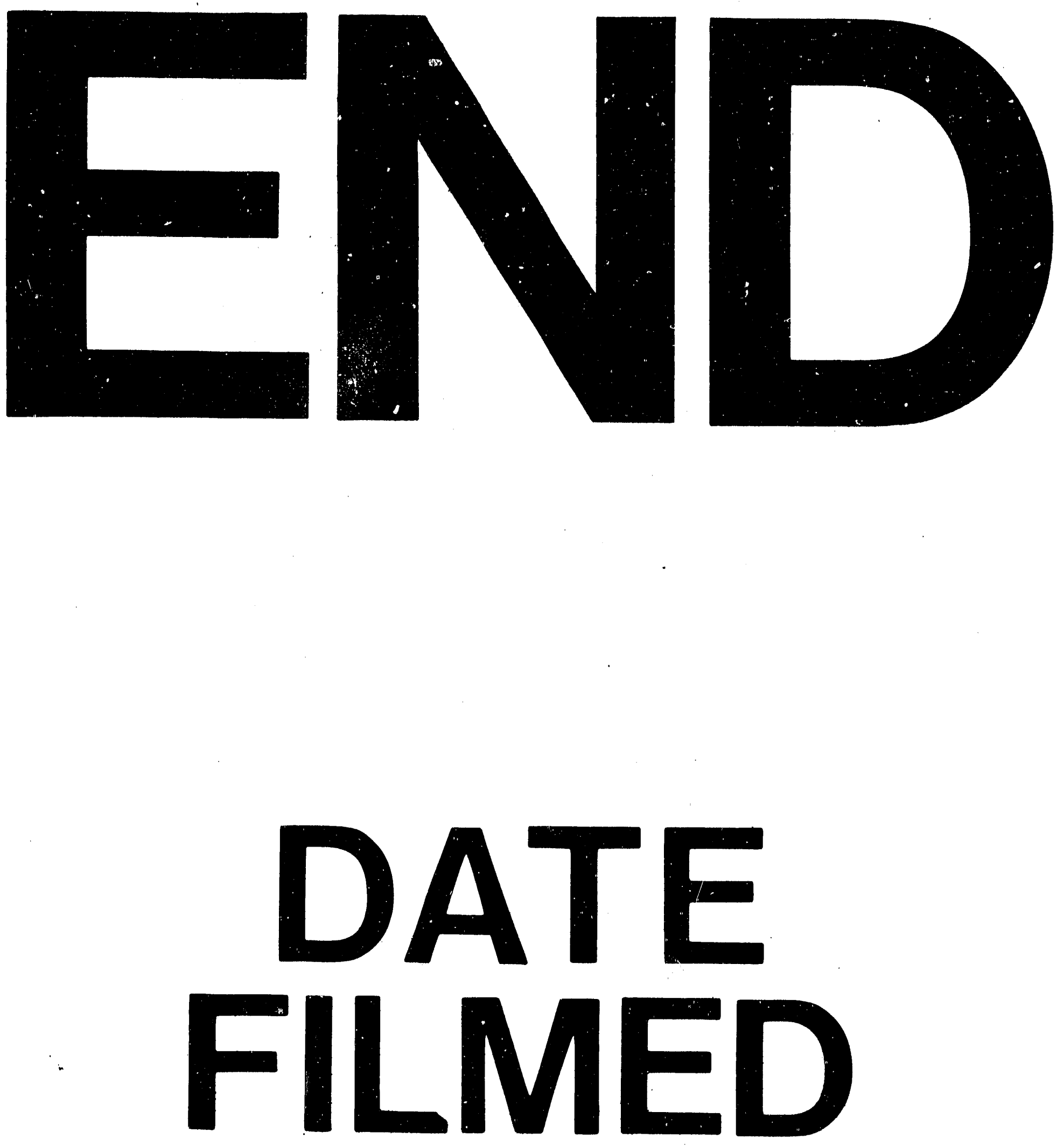

1

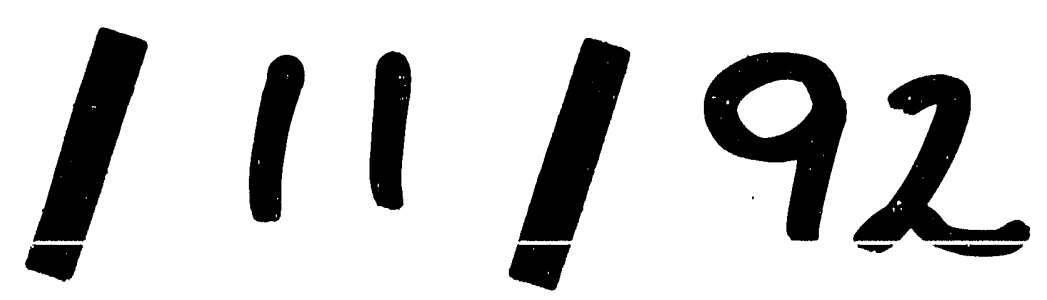


